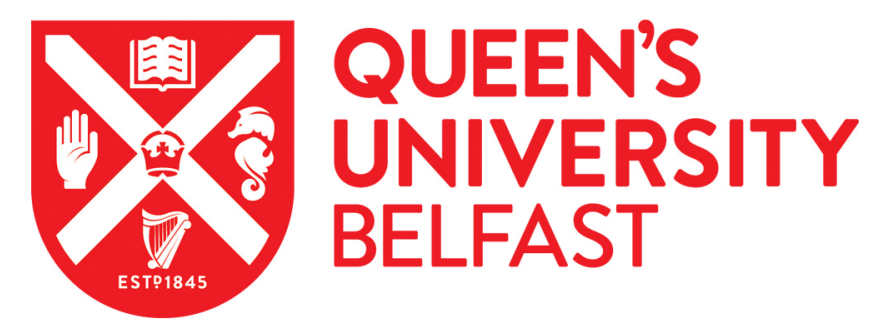

\title{
Fading Characteristics of Body-to-Body Channels Subject to Vehicular Traffic Conditions at $2.45 \mathrm{GHz}$
}

Doone, M. G., \& Cotton, S. L. (2014). Fading Characteristics of Body-to-Body Channels Subject to Vehicular Traffic Conditions at $2.45 \mathrm{GHz}$. In Proceedings of 2014 IEEE Antennas and Propagation Society International Symposium (APSURSI) Institute of Electrical and Electronics Engineers Inc.. https://doi.org/10.1109/APS.2014.6904692

Published in:

Proceedings of 2014 IEEE Antennas and Propagation Society International Symposium (APSURSI)

Document Version:

Peer reviewed version

Queen's University Belfast - Research Portal:

Link to publication record in Queen's University Belfast Research Portal

Publisher rights

(c) 2015 IEEE. Personal use of this material is permitted. Permission from IEEE must be obtained for all other uses, in any current or future media, including reprinting/republishing this material for advertising or promotional purposes, creating new collective works, for resale or redistribution to servers or lists, or reuse of any copyrighted component of this work in other works.

\section{General rights}

Copyright for the publications made accessible via the Queen's University Belfast Research Portal is retained by the author(s) and / or other copyright owners and it is a condition of accessing these publications that users recognise and abide by the legal requirements associated with these rights.

Take down policy

The Research Portal is Queen's institutional repository that provides access to Queen's research output. Every effort has been made to ensure that content in the Research Portal does not infringe any person's rights, or applicable UK laws. If you discover content in the Research Portal that you believe breaches copyright or violates any law, please contact openaccess@qub.ac.uk. 


\title{
Fading Characteristics of Body-to-Body Channels Subject to Vehicular Traffic Conditions at $2.45 \mathrm{GHz}$
}

\author{
Michael G. Doone and Simon L. Cotton \\ ECIT Institute, Queen's University Belfast, BT3 9DT, United Kingdom \{mdoone03, simon.cotton\}@qub.ac.uk
}

\begin{abstract}
In this paper we investigate the small-scale fading characteristics of body-to-body communications channels in an urban environment at $2.45 \mathrm{GHz}$. The experiments considered body-to-body channels between devices positioned on two persons on either side of a busy road. The Ricean- $K$ factors estimated from the measurements suggest that a significant dominant component existed in the majority of the channels.
\end{abstract}

\section{INTRODUCTION}

In the future greater social integration and cooperation will see wireless devices situated on different people sharing information and also being used to relay data meant for other people and networks [1]. Vast body-to-body networks (BBNs) formed by devices carried or worn by people will begin to emerge. For this new type of wireless system, node mobility and the effects of moving objects in the local vicinity will play an important role in determining the propagation characteristics of the channel.

It has already been established that passerby effects caused by another human body which is not part of the network can have an impact on body centric communications channels [2]. In [2], the authors investigated the characteristics of on-body channels used in body area networks (BANs) which were perturbed by the movement of another person in the local vicinity. It was found that for on-body channels exhibiting fluctuations greater than $20 \mathrm{~dB}$, the Rice fading model provided a good fit to the measured data.

Shadowing in body-to-body (B2B) channels at $2.45 \mathrm{GHz}$ has been studied in [3]. It was found that B2B channels are particularly vulnerable to shadowing as they can suffer from dual node shadowing where both person's bodies obstruct the main signal path causing the link to be lost altogether even at very short separation distances of a few meters. However this study only considered shadowing caused by the person's forming the B2B link and did not consider fading caused by objects moving in the local area such as pedestrians and vehicles. In this paper we use the Rice fading model [4] to characterize the small-scale fading in B2B channels at $2.45 \mathrm{GHz}$ which are subject to uncontrolled vehicular traffic conditions within a busy urban environment.

\section{MEASUREMENT SySteM, ENVIRONMENT AND PROCEDURE}

A series of narrowband B2B channel measurements were performed using purposely developed wireless nodes. The RF section of the bespoke wireless nodes featured an ML2730 transceiver chip manufactured by RFMD. The radio registers on the ML2730 transceiver were programmed using a PIC32MX microcontroller which acted as a baseband controller. For the duration of the experiment, one node was programmed to transmit a continuous wave signal at $2.45 \mathrm{GHz}$ with an output power of $+21 \mathrm{dBm}$. The receiver nodes were set up to sample the Receive Signal Strength Indication (RSSI) at a 10-bit quantization depth with a sample rate of $2 \mathrm{kHz}$. A total of 2,515,613 RSSI samples were collected for the data analysis presented in this study. The antennas used at both the transmitter and receivers were $+2.3 \mathrm{dBi}$ sleeve dipole antennas (Mobile Mark model PSKN3$24 / 55 \mathrm{~S})$. These were connected directly to the wireless node's using an SMA connector. For the duration of the experiments all of the antennas were vertically polarized.

The location for the measurement campaign was a typical busy urban street in Belfast, UK. It should be noted that this was a speed restricted environment in which a maximum speed of $30 \mathrm{mph}$ is permitted. As shown in Fig. 1, the area consisted of a straight road bordered by houses and trees. To deliver a comprehensive characterization of the B2B channel, four body locations on both persons were considered. A transmitter node was initially attached to the central chest region of person $\mathrm{A}$ and then alternated between the central chest, right wrist and right jacket pocket. Four receiver nodes were placed at the central chest and waist, left wrist and left jacket pocket of person B for the duration of the experiments. This setup permitted sixteen different body-to-body channels to be analyzed. Each channel was studied under five different scenarios while random traffic crossed the paths of the channel. The five measurement scenarios were (Fig. 1):

1. Persons A and B stationary while directly opposite at locations A1 and B1 respectively,

2. Person B standing stationary (B1) with person A walking at a normal pace $\left(\sim 1.2 \mathrm{~ms}^{-1}\right)$ from location $\mathrm{A} 1$ to $\mathrm{A} 2$,

3. Person B standing stationary at location B1 with person A walking from location A2 to A1,

4. Persons $\mathrm{A}$ and $\mathrm{B}$ walking from location $\mathrm{A} 1$ and $\mathrm{B} 1$ to $\mathrm{A} 2$ and $\mathrm{B} 2$ respectively,

5. Person A starting from A2 and walking towards A1 while person B simultaneously walks from B1 to B2.

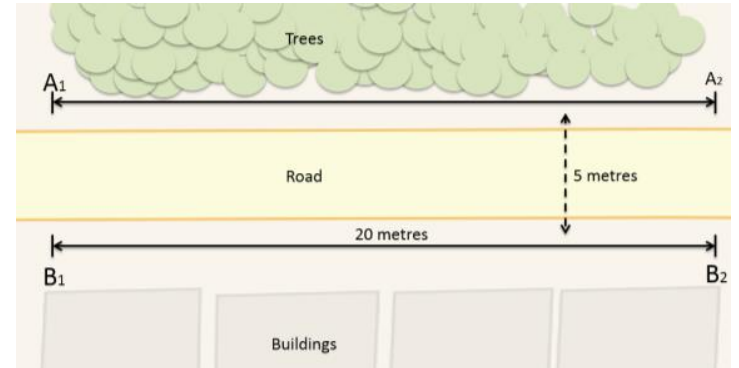

Fig. 1 Top view of measurement environment showing body trajectories. Both bodies were orientated parallel to the roadside for the duration of the experiments. 


\section{RESULTS}

Fig. 2(a) shows the sampled received signal power time series for the chest-to-chest channel in scenario 1 . To extract the small-scale fading observed in these B2B channels, a moving average of 500 samples was applied to the original signal to obtain the local mean signal power [Fig. 2(b)]. The local mean signal was then removed from the measured channel data [Fig. 2(c)]. Using maximum likelihood estimation, the parameter estimates of the Rice probability density function (PDF) most likely to have generated the small-scale fading were obtained. Ricean fading is often characterized using the Ricean $K$ factor [4]. Here $K$ is defined as the ratio of the signal power of the dominant component to the total scattered power. Table I shows the estimated Ricean $K$ factors for all of the B2B channels considered in this study.

As we can see from Table I, the highest estimated $K$ factors were obtained for the B2B channels in which both persons were stationary (scenario 1 ). Here $K$ ranged from 3.28 for the pocket-to-wrist channel to 50.33 for the waist-to-waist channel. If we consider the chest-to-chest channel depicted in Fig. 2, the main source of variability in this channel was caused by the passing vehicles intersecting the main signal path. This can be observed in the received signal power and local mean time series [Figs. 2(a) and (b)]. Nonetheless, this channel was dominated by a strong signal component as illustrated by the estimated $K$ factor which was found to be 31.63 (Table I).

Fig. 3 shows an example of the Rice CDF fitted to the measured data from scenario 2 while the transmitter was at the chest position. As we can see it provides an excellent fit to the data. In general when either end of the B2B link became mobile, a reduction of the estimated $K$ factors was observed caused by the increased variability in the channel due to node mobility and interaction with the surrounding environment. In particular, for scenario 2, when person A walked away from person B, so that their body shadowed the main line of sight paths, the estimated $K$ factors were significantly reduced compared to scenario 1 . It is worth noting that the estimated $K$ factors for all of the scenarios were always greater than zero suggesting that a dominant signal component was always present.

\section{CONCLUSION}

A study of B2B channels operating at $2.45 \mathrm{GHz}$ with the influence of passing traffic in an urban environment has been investigated. The Rice fading model has been applied to the measured data and the Ricean $K$ factor used to characterize the small-scale fading. It was found that the Ricean $K$ factor was always greater than zero, with B2B channels in which both persons are stationary experiencing the least fading.

\section{REFERENCES}

[1] S. L. Cotton and W. G. Scanlon, "Using smart people to form future mobile wireless networks, " Microwave Journal, vol. 54, no. 12, pp. 24 40,2011

[2] T. S. See, T. M. Chiam and Y. Ge C. W. Kim, "Channel Characterization of Walking Passerby's Effects on 2.48-GHz Wireless Body Area Network," vol. 61, no. 3, pp. 1495- 1498, March 2013.

[3] S. L. Cotton, "A statistical model for shadowed body centric communications channels: theory and validation," accepted for publication, IEEE Transactions on Antennas and Prop., October 2013.

[4] G. L. Stüber: Principles of Mobile Communication, 3rd Edition, Springer 2011.
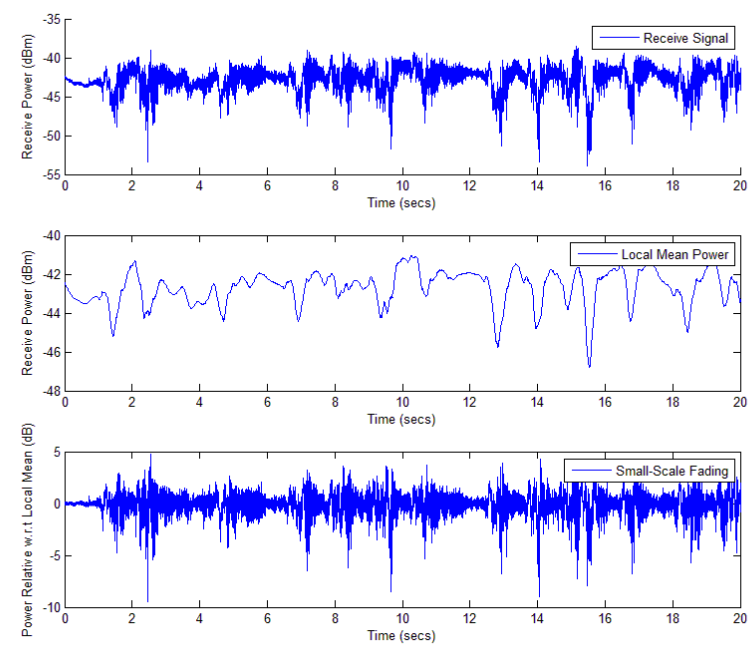

Fig. 2 Twenty second excerpt of (a) the received signal power time series, (b) the local mean signal power and (c) the small scale fading for the chest to chest channel in scenario 1 .
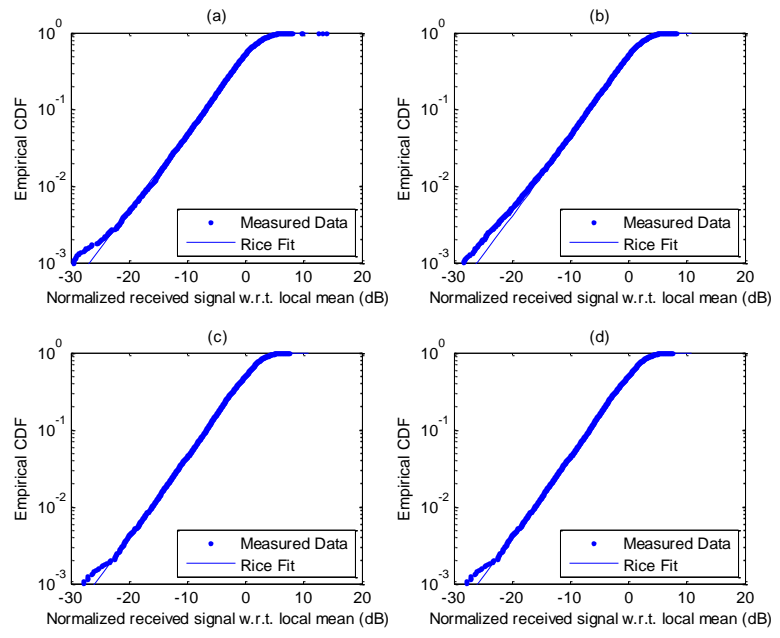

Fig. 3 Empirical and theoretical CDF plots for chest to (a) chest (b) waist, (c) wrist and (d) pocket for scenario 2 .

TABLE I. RICEAN $K$ FACTORS FOR ALL EXPERIMENTAL SCENARIOS.

\begin{tabular}{|c|c|c|c|c|c|c|c|c|c|c|c|c|c|c|c|c|c|c|c|c|}
\hline \multirow{2}{*}{$\begin{array}{c}\text { Body A/ } \\
\text { Body B }\end{array}$} & \multicolumn{5}{|c|}{ Chest } & \multicolumn{5}{|c|}{ Waist } & \multicolumn{5}{|c|}{ Wrist } & \multicolumn{5}{|c|}{ Pocket } \\
\hline & 1 & 2 & 3 & 4 & 5 & 1 & 2 & 3 & 4 & 5 & 1 & 2 & $\mathbf{3}$ & 4 & 5 & 1 & 2 & $\mathbf{3}$ & 4 & 5 \\
\hline Chest & 31.63 & 1.48 & 11.40 & 0.95 & 1.15 & 13.60 & 1.78 & 5.21 & 1.13 & 1.41 & 3.86 & 1.85 & 4.31 & 1.15 & 0.76 & 3.86 & 1.85 & 4.31 & 1.15 & 0.76 \\
\hline Waist & 30.64 & 1.28 & 4.39 & 1.19 & 1.44 & 50.33 & 1.77 & 3.49 & 1.24 & 1.95 & 15.94 & 1.46 & 2.63 & 1.28 & 1.39 & 48.16 & 1.77 & 2.21 & 1.43 & 1.04 \\
\hline Wrist & 16.53 & 2.92 & 2.16 & 4.84 & 1.91 & 14.76 & 3.12 & 2.77 & 2.29 & 2.27 & 5.33 & 2.56 & 2.54 & 5.07 & 1.58 & 3.28 & 2.24 & 2.07 & 2.23 & 1.43 \\
\hline Pocket & 41.30 & 1.99 & 2.29 & 1.53 & 2.23 & 40.53 & 2.01 & 2.29 & 1.23 & 2.65 & 18.71 & 0.86 & 2.98 & 1.28 & 1.32 & 29.95 & 1.30 & 4.91 & 1.53 & 1.08 \\
\hline
\end{tabular}

